\title{
SUSTAINABILITY VALUE CHAIN IN BIOECONOMICS
}

\author{
N. Penev, Y. Andreev* \\ Faculty of Economics, Trakia University, Stara Zagora, Bulgaria
}

\begin{abstract}
The concept of bioeconomics covers all sectors of the economy, including agriculture, which supplies renewable resources: plants, animals, microorganisms and their processed products. The goal is a transition to an economy that is independent of fossil fuels and non-renewable resources. Agriculture and forestry, fisheries and aquaculture, as well as the conversion of biotechnological biomass and biological waste, are central to the multilateral new value chain. The processing industry uses renewable resources in various products, in particular, due to the industrial application of biotechnological and microbiological processes, especially in the chemical industry. This also applies to the food, woodworking, paper, construction, leather, and textile industries, as well as parts of the pharmaceutical and energy industries. Thus, the cyclic system and the storage of reusable waste are also included in the bioeconomic system. The aim of our study is to study the degree of development of sustainable value chains in bioeconomics.
\end{abstract}

Key words: value chains, cyclic bioeconomics, closed cycle bioeconomics, prospects of the bioeconomy

\section{INTRODUCTION}

In the past few decades, we have been faced with the emergence of a single and closely interconnected socio-ecological system on a global scale. The whole world, and in particular Europe, are faced with an unprecedented number of related problems that will grow in the coming years. We are talking about the growing demand for food, water, resources and energy and at the same time about ongoing processes to combat climate change and environmental degradation, including loss of biodiversity, air emissions and soil degradation. Addressing these complex issues, along with the need to support the socio-economic prosperity of a growing population, requires systematic changes in our economic model.

After the First Industrial Revolution and during the following two and a half centuries, the world economy was built mainly upon the use of fossil raw materials and upon the approach of a linear economy. We were witnesses how

\footnotetext{
*Correspondence to: Nikolay Penev Ivanov, Student campus, Trakia University, Faculty of Economics, 6000, Stara Zagora, Bulgaria, e-mail: penevbg@abv.bg
}

the world's population changed, as it has never done before. The industrial age brought its economic and demographic growth, as well as social and technological progress. Over the past half century, the world economy has grown significantly, which has led to significant cross-border economic convergence and a significant reduction in the level of poverty and inequality between rich and poor countries.

Unfortunately, the industrial era not only brought enormous economic growth but also seriously deteriorated the fragile balance of the environment and has led to a series of environmental disasters. Back in 2015, it became clear that the level of sustainable use of planet resources was exceeded 1.6 times. This means that in two decades, two planets will be needed to maintain the modern economic system.

As early as February 13, 2012, the European Commission adopted the strategy "Innovation for Sustainable Growth: Bioeconomics for Europe" [1]. In recent years, many countries of the world and Europe have developed their own bioeconomic development strategies. In 2017, the EU began an audit of the existing 
bioeconomic strategy in order to elaborate on its future development.

We are convinced that bioeconomics itself is very difficult to develop, therefore it is better to keep it in a closed cycle. Therefore, bioeconomics has significant potential for accelerating the development of a panEuropean economic system - a political and social project, the need for which is becoming ever more acute.

The transition to a sustainable bio-economic closed-cycle paradigm should include all possible links in the chain of value, which will help overcome the interdependence between economic growth and environmental degradation.

\section{WHAT IS BIOECONOMICS?}

There are many definitions of the term bioeconomics that use similar terms, such as bioeconomics and green economy. In practice, bioeconomics has proven to be a flexible concept that applies to many goals. Here we will adopt the definition given by the European Commission defining bioeconomics as "the production of renewable biological resources and the conversion of these resources and waste streams into value-added products such as food, animal feed, bio-based products and bioenergy. Its sectors and industries have strong innovative potential through the use of a wide range of scientific advances, stimulating both industrial technologies, as well as local knowledge and hidden knowledge. "[1]. However, we will focus on two main aspects:

- the transformative role of bioeconomics in replacing fossil products (for example, oilbased plastics or textiles), non-renewable materials (for example steel, concrete) or biological products that violate sustainability principles (for example, cotton in some regions);

- Improvement of the approach to the use of natural capital in the economy, ie closer integration of the value of natural resources and life support systems (for example, biodiversity, fresh water supply) in economic development [2].

The first part, as a rule, is already well understood in bioeconomic strategies, the second - to a lesser extent. Long-term sustainable production of natural capital depends on the key role of forests as the most important terrestrial biological infrastructure on the European continent. Finally, although this problem does not specifically solve this problem, we understand that the combination of digital technologies with biology can provide significant progress in bioeconomics in the future.

Bioeconomics covers a wide range of products and industries (as well as services), such as construction, bioplastics, packaging materials, food ingredients, textiles, chemical and pharmaceutical products, and bioenergy. This also includes services related to biomaterial products, such as intellectual property rights, consulting, research, and development, marketing, sales, maintenance, administration and much more. Ecosystem services such as recreation, tourism and water supply are also part of bioeconomics. Despite its importance for various sectors, bioeconomics must be considered comprehensively, given its full potential to provide broad social, economic and environmental benefits at a Community level.

\section{ON THE WAY TO A NEW LEVEL OF DEVELOPMENT: CLOSED CYCLE BIOECONOMICS}

Closed-cycle bioeconomics is associated with economic activities that recycle waste from other industries, and ultimately, the waste discharged into nature is extremely little and must also decompose quickly. In addition, bioeconomics focuses on the development of products undergoing a separation / disassembly cycle of components and reuse, as well as waste recycling. This allows you to replace fossil, non-renewable and non-degradable materials with renewable and biodegradable. In addition, bioeconomics can offer new features for bio-based materials, such as longer service life, higher durability, less or zero toxicity, etc., which a closed-loop economy cannot offer on its own. Therefore, a combination of two concepts - a feedback economy and bioeconomics - makes sense and creates the conditions for synergy. [3] Bioeconomics and closed-loop economies alone do not imply sustainable development; they should be based on the principles of sustainability. To this end, it is imperative that biomaterial production does not compete with food production and does not adversely affect other ecosystem services (biodiversity, protection from climate change and natural disasters, etc.).

At the same time, a closed-loop economy should reduce its dependence on fossil and non-renewable materials with a high level of 
environmental impact. An integral part of creating synergies is assessing how biomass and biodegradable materials are stored in a closed-loop economy, for example, they are easy to reuse in production.

Closed-loop bioeconomics, or "circular bioeconomics," includes several strategic levels that must be achieved in order to be considered sustainable. These are:
- economic level - improving the economic development of the region

- $\quad$ social level - improving people's lives by providing healthy food and less pollution

- biological level - improving the biosphere of our planet, maintaining species' diversity and stopping climate change

In this case, we can introduce circular bioeconomics using the following figure:

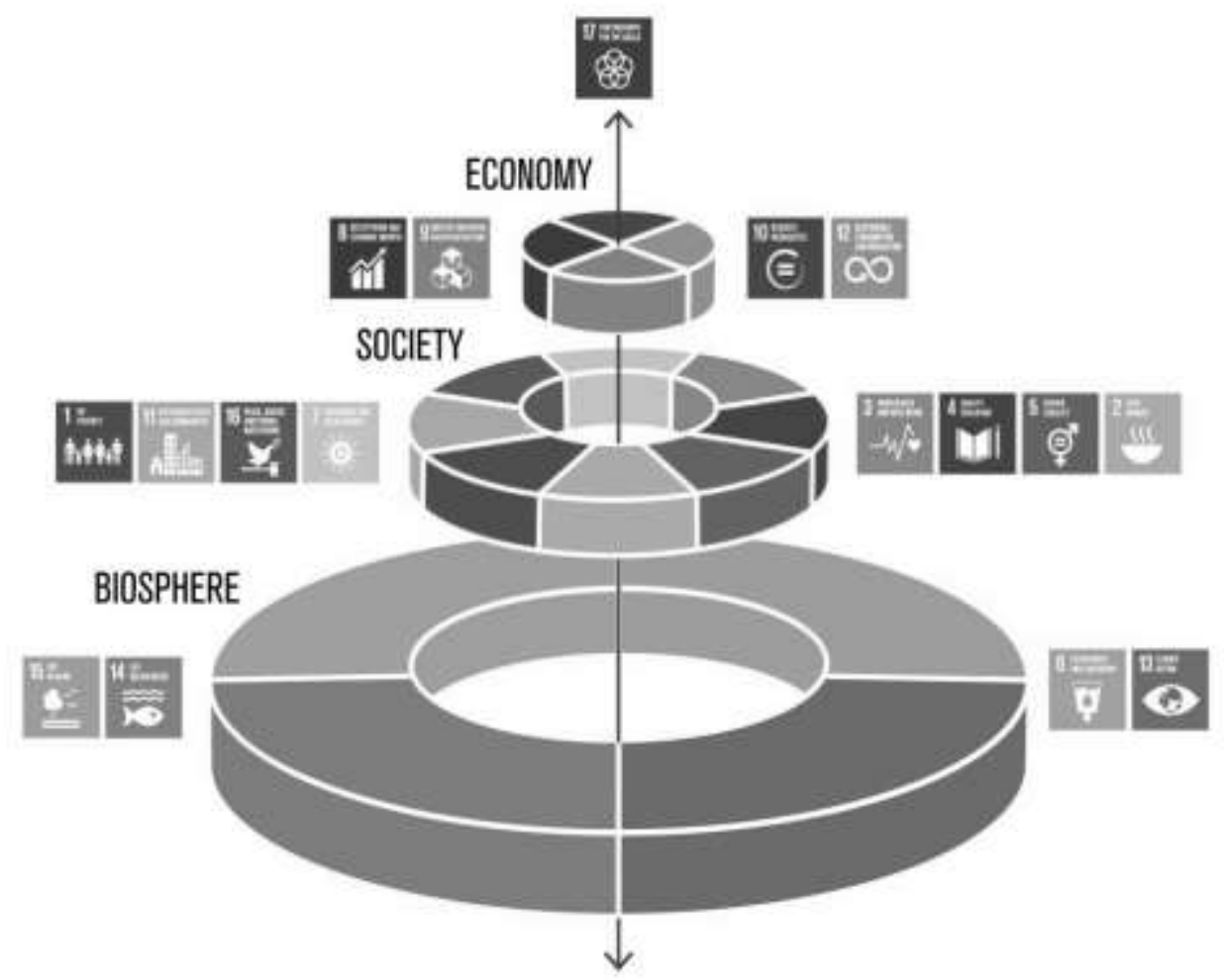

Figure 1. Sustainable development levels that form the basis of a closed-loop bioeconomy strategy Source: Azote Images for Stockholm Resilience Centre.

\section{VALUE CHAIN IN THE CIRCLE BIOECONOMICS}

The engine of sustainable development in the field of bioeconomics is the use of a value chain that is associated with bioprocessing (the creation of a biofactory). The development of biofactory technologies allows for a smooth transition from a traditional linear economy based on fossil hydrocarbons to bio-processed foods and environmentally friendly technology based on renewable raw materials (biomass). The term "bio" in relation to bioeconomics does not have environmental significance, but economic value when value chains are based on technologies based on knowledge of life sciences.

In this context, the development and provision of products and services based on biological resources clearly requires an emphasis on the assessment of economic, environmental and social consequences. This can only be decided in collaboration between experts representing different points of view on sustainability. The supply of products based on bio, biofuel, and other products of cyclic bioeconomics can be sustainable only if all stages of the production process, from the supply of biomass to use, meet the basic criteria of sustainability. This requires thinking in a complete value chain. In addition, resource efficiency can be best achieved by coordinating the various steps of the process in the value chain.

The sustainability of the value chain in bioeconomics is directly related to the principles of a circular economy. The whole process of organizing sustainable bioeconomics cannot occur without the participation of the value chain, as well as the circular economy. All of these elements enable bioeconomics to function stably. 


\section{SUSTAINABLE DEVELOPMENT OF THE CIRCLE ECONOMY}

Sustainable development should be at the center of bioeconomics. At the end of the 20th century, sustainable development is associated with the search for harmony between the economy, society and the environment. This sustainability is now seen as economic development that supports the prosperity and well-being of the entire human society, but within the given environmental boundaries on a local, regional and planetary scale. This new approach to human development can provide synergies with the development of ecosystems and the conservation of their biodiversity.

History has shown that markets do not automatically lead to sustainable development. A certain policy is needed to avoid depletion of resources and other undesirable external effects that markets can create, as well as to increase the cost of services that are not sold in markets. In particular, the policy of monitoring, evaluating and ensuring the sustainability of the bioeconomy. In this way, side effects can be avoided, and a closed cycle bioeconomy which creates a value chain with great potential for people and our planet. [4]

The first significant feature of bioeconomics with feedback is that it considers sustainability in the value chain at an early stage, for example, at the design stage of production chains and consumption patterns. This means that companies and government agencies are addressing potential sustainability issues using the best available knowledge and production cycle information in addition to market and technology issues. Scientific developments in new products and materials include testing for a potentially high environmental risk or unacceptable burden. As history lessons show, such screening can use prognostic tools and can lead to significant sustainability and business benefits. In the past, we saw examples of promising new technologies that subsequently proved harmful to people or the environment, such as the production and use of DDT or asbestos cement. The regulatory role of public authorities is to apply the precautionary principle to promote sustainable progress, but this should not threaten the environment and human health.

Another essence of sustainable circular bioeconomics is to think about the whole life cycle. Potential environmental impacts should
PENEV N., et al.

be avoided throughout the life cycle of products and services, from the stage of resource extraction, then during the production process to the phase of use and, finally, the reuse of processed resources in new products. At the end of the service life, simple waste management should be avoided, for example, in the case of wood products; this can be conversion to energy and the use of ash as a fertilizer or building material.

Life cycle thinking can be integrated into policies that stimulate industrial symbiosis, increase the value of waste and set a high price for it, or prohibit its destruction. Problems with the sustainability of the value chain in bioeconomics throughout the life cycle are either related to the resources consumed, i.e. caused by the extraction of resources from the natural environment or are associated with the production of products, i.e., caused by emissions into the environment during its production, use or end of the operation. Environmental risks associated with consumed resources are very important for bioeconomics, since the economy relies mainly on biotic resources, such as biomass, and on the necessary land resources for its cultivation. The challenge is to use these limited resources through sustainable development.

A huge asset of biotic resources is that they can be renewable - they can be grown again and again after harvest. This does not apply to non-renewable resources, such as gasoline, metal ores or phosphates, for which, if rich deposits are depleted, production stops forever. But the condition for using renewable biotic resources is their sustainable use that is, preventing the disappearance of the resource base. But this requires proper management. For example, in forests, this requires planning, which regulates the yield of wood, maintaining a sufficiently large volume of growing forests to ensure its further growth.

Another category related to consume resources is the nature of land use. Replacing fossil resources with biological resources can lead to an increase in land scarcity, which will lead to higher land prices and may increase potential conflicts between different land uses. A wellknown example of a conflict between land-use options is the fuel-fuel debate that arose when the introduction of corn ethanol subsidies in the United States contributed to food shortages and the global food price crisis in 2007-2008. 
In fact, land allocation problems are inherent in any economy based on their use, but they can be resolved using appropriate value-added management policies and practices that support land use optimization and address environmental and social issues. [5]

Cyclical bioeconomics of the future can reduce land-use risks by optimizing land use, taking into account trade-offs and synergies between different ecosystems, and then focusing on a reasonable combination of combined land use and landscape-oriented land use.

An economy based on the use of biological resources, which relies on continuous supplies of raw materials from ecosystems, is particularly vulnerable to changes in environmental conditions, especially climate change. Without appropriate measures to adapt to climate change, sustainable management of biotic resources and mitigating effects on climate change are not possible. This applies to all ecosystems, including forests, agricultural systems, and fisheries. [6]

\section{CONCLUSION}

In conclusion, we can say that the value chain in circular bioeconomics will be a key tool for achieving sustainable development. Through the value chain, bioeconomics can help preserve biodiversity and mitigate climate change.

To stimulate the circular bioeconomy and value chain, a much higher cost of $\mathrm{CO} 2$ emissions is needed than its current level. In this regard, it is urgent to stop subsidizing the production of fossil fuels. The real cost of fossil fuel subsidies, which includes both direct subsidy costs and indirect environmental costs, in the EU in 2013 was close to $\$ 300$ billion. [7]

Investments in research, development, and innovation need to be increased in order to strengthen the foundations of feedback-based bioeconomics. In addition to intensifying the development of organic products, it is necessary to better understand the role of the value chain and to contribute to enhancing its
PENEV N., et al.

role. This will become an integral and increasingly important part of a successful and sustainable circular bioeconomy.

Bioeconomics should also be seen as a key strategy for urban areas, not just in rural areas, as is traditionally done. Closed-loop bioeconomics will not be successful if the urban population does not see their place in it. To support public participation, a scientifically based supply chain concept in circular bioeconomics and an effective link between all elements of the chain and bioeconomics are needed.

\section{REFERENCES}

1. Innovating for sustainable growth: A bioeconomy for Europe - https://eurlex.europa.eu/legalcontent/BG/TXT/?uri=CELEX\%3A52012 DC0060

2. Helm, D., 2015. Natural Capital: Valuing The Planet. Yale University Press

3. Antikainen, R. et al. 2017. Renewal of forest based manufacturing towards a sustainable circular bioeconomy. Reports of the Finnish Environment Institute 13/2017. https://helda.helsinki.fi/handle/10138/1860 80

4. Griggs, D., Stafford-Smith, M., Gaffney, O., Rockström, J., Öhman, M.C., Shyamsundar, P., Steffen, W., Glaser, G., Kanie, N., and Noble, I., 2013. Sustainable development goals for people and planet.

5. Phalan, B., Onial, M., Balmford, A., and Green, R. E., 2011. Reconciling food production and biodiversity conservation: land sharing and land sparing compared. Science, 333(6047)

6. Hanewinkel, M., Cullmann, D.A., Schelhaas, M.J., Nabuurs, G.-J., and Zimmermann, N.E., 2013. Climate change may cause severe loss in the economic value of European forest land. Nature Climate Change 3

7. Coady, D., Parry, I., Sears, L. and Shang, B., 2017. How large are global fossil fuel subsidies? World Development, vol. 91, issue $\mathrm{C}$ 